\title{
Attachment mechanisms of epiphytic orchid seeds reconsidered
}

\author{
Rasmussen H.N. ${ }^{1 *}$ \& F.N. Rasmussen ${ }^{2}$ \\ 'Senior Scientist, University of Copenhagen, Department of Geosciences and Natural Resource Management, \\ Rolighedsvej 23, 1958 Frederiksberg C, Denmark \\ ORCID-ID: 0000-0002-0181-9304 \\ 2Professor Emeritus, University of Copenhagen, Natural History Museum of Denmark, Øster Voldgade 5-7, Copenhagen K, Denmark \\ ORCID-ID: 0000-0002-8282-8594 \\ *E-mail: hnr@ign.ku.dk
}

\begin{abstract}
Orchid seeds generally are "dust" seeds with adaptations towards wind dispersal, and they have many features in common throughout the family. Epiphytism has evolved only within certain subgroups of the Orchidaceae, and it is unclear what seed adaptations favour epiphytism, as compared to the terrestrial lifeform. Seed attachment to bark has attracted very little attention in orchid biology. So far, Chiloschista lunifera (Rchb.f.) J.J.Sm. is the only species reported to have an actual attachment mechanism. In this study, we attempt to confirm old records of seed coat mucilage production in 15 test species, and provide data on seed weights and lengths to test differences according to life form. Uptake of water and seed attachment are likewise compared. Seeds of epiphytic species tended to be shorter than those of terrestrials. In epiphytic species we found cases of very fast germination, within $20 \mathrm{~h}$ of exposure to water. Mucilage production could not be demonstrated microscopically. Attachment of dry seeds to a vertical smooth surface was generally high, in both epiphytic and terrestrial species, but in many species attachment was increased by previous water exposure.
\end{abstract}

Keywords: Bark ecology, Dispersal, Mucilage, Myxospermy, Testa.

\section{Introduction}

Surveys of orchid seed morphology display a great variation in sizes and shapes. However, except for a few special cases, such as in Vanilloideae, orchid seed morphology appears to be largely variations

Received: 31.03.2021; Revised \& Accepted: 17.09.2021

Published Online: 16.10.2021 upon the same basic structure, in the words of Barthlott et al. (2014: 13) is "rather conservative". In spite of the great difference in germination niche, it is surprisingly hard to tell seeds of terrestrial species from those of epiphytic species on outer morphology. Nevertheless, a considerable amount of diversity appears to exist in respect to chemical surface characteristics in orchid seeds (Barsberg et al., 2018) - an insufficiently explored diversity that so far cannot be linked to germination strategies.

A limited number of published reports aim to contrast epiphytic and terrestrial orchid species with respect to seed physiology and germination patterns. Within Liparis (L.) Rich. an epiphytic species could germinate at higher light intensity than related terrestrial species, but protocorm development was nevertheless dependent on low light exposure in all species (Tsutsumi et al., 2011). This suggests that epiphyte germination is tolerant to strong light exposure in tree canopies, and may explain why terrestrial species have no success in that habitat. However, young seedlings need to be protected from water loss in all habitats. In epiphytes such protection could be by emerging phorophyte foliage. Water is taken up and lost much faster in the epiphytic species than in terrestrial ones, consistent with a more rapid germination (Yoder et al., 2000, 2010).

Apart from enduring the conditions in the canopy during their germination, the epiphytic species all 
need to stay attached when the seeds lodge on a bark surface, and sometimes do so against gravity. The only pronounced attachment mechanism described in Orchidaceae is that of Chiloschista lunifera (Rchb.f.) J.J.Sm. (Barthlott \& Ziegler, 1980): in contact with a drop of water on a glass plate, the seeds at first were strongly water repellent and floating. However, as the micropylar end sank to touch the solid surface below the water, the testa cells elongated within 3-10 seconds, cell walls dissolved and released mucilage. The attachment mechanism thus had two components: the cellulose strands released from the dissolving testa cell walls, which will tend to cling to any irregularity of a substrate surface, and the mucilage, functioning as a glue. Barthlott and Ziegler (1980) tested these seeds on bark of Pinus sp. and Vitis sp., and after drying out, the firmly attached seeds could only be removed by damaging force. The authors did not find any similar mechanisms in the numerous other orchid species they studied.

Since all epiphytic species would seem to need attachment, we asked the question whether Chiloschista lunifera just represents the pinnacle of adaptations to seed attachment. Production of mucilage in seeds is widespread throughout the plant kingdom (Grubert, 1974) and is a less conspicuous feature than exploding testa cells. Considering that we usually observe orchid seed germination only after surface sterilisation, it seemed possible that such excretions might have been overlooked. However, there are a few previous reports - if somewhat uncertain - to support the idea of more attachment mechanisms in orchid seeds. In a species of Aerides Lour. , cells constituting the outer integument form rims where the anticlinal walls meet; these rims were reported to partly dissolve in water and bend as attachment hooks (Netolitzky, 1926, citing Beer 1863). However, Beer (1863) did not mention any such devices. Mucilage in seeds of Renanthera Lour. spp. appears to have been reported by Brown, according to Pammel (1892, in a paper on seeds in Euphorbiaceae!). This information was repeated in
Grubert's works $(1974,1981)$ but we have not been able to verify the original source.

With this in mind we established a small collection of seeds representing a range within Orchidaceae, both terrestrial and epiphytic species (Table 1) and tested if we could confirm mucilage production in any of the species. The actual attachment to surfaces was also investigated.

\section{Materials and Methods}

\section{Materials}

Fifteen species were available for study, representing all subfamilies except Vanilloideae (Table 1). They represented terrestrial and epiphytic lifeforms almost equally. Since only one species was included from each genus, they will be referred to here by generic names.

\section{Methods}

a. Seed weights: A Mettler Toledo AX 205 Deltarange (Columbus, USA) balance with a resolution of $\pm 5 \mu \mathrm{g}$ was used. For each species, the balance was tared with an aluminium cup weighing 350-400 mg. A load of dry seeds (20-200) was subsequently weighed and counted, and the mean single seed weight calculated. Three assessments were made for each species and a mean calculated. The measurements are subject to uncertainty as there were seed fragments, and some of the seeds lacked embryos; accepting them as seeds would lead to an underestimation of the average full seed weight, while on the other hand excluding them would lead to an overestimation. We attempted to count imperfect seeds as seeds, as long as they had morphologically normal testa, and did not count fragments. Seed weights of terrestrial and epiphytic species were compared by Mann-Whitney U-test.

b. Test for mucilage production: Ruthenium Red solution was prepared: $40 \mathrm{mg}$ ruthenium (535, Aldrich 703206, St. Loius, USA) in $50 \mathrm{ml} \mathrm{Milli-}$ Q® water (Elga Purelab Flex, High Wycombe, $\mathrm{UK}$ ) and $1 \mathrm{ml} 20 \% \mathrm{w} / \mathrm{v} \mathrm{NaOH}$. Seeds were placed 
Table 1. Seed materials of the 15 orchid species used in the present study. Species names in accordance with WCSP (2020). Subfamiliar, tribal and subtribal affiliation according to Chase et al. (2015). P-numbers refer to the collection of the Botanical Garden, Copenhagen, four-digit numbers to the seeds donated by Henrik Ærenlund Pedersen and originating from his seed production project of Asian species, mainly Thailand. Seeds of E. helleborine were from a spontaneous occurrence in the authors' garden in Denmark, $P$. aphrodite and $N$. veratrifolia are collections from the greenhouse of the National Museum of Natural Science, Taichung, Taiwan. Seeds of C. calceolus were remains from a study of natural populations in Denmark (Pedersen et al., 2012).

\begin{tabular}{|c|c|c|c|c|}
\hline Species & subfamily & Tribe/subtribe & lifeform & Material \\
\hline Neuwiedia veratrifolia Blume & Apostasioideae & & terrestrial & $\begin{array}{l}\text { Taichung, } \\
\text { Taiwan }\end{array}$ \\
\hline Cypripedium calceolus $\mathrm{L}$. & Cypripedioideae & & terrestrial & Denmark \\
\hline Odontochilus lanceolatus (Lindl.) & Epidendroideae & Cranichideae/Goodyerinae & terrestrial & 0137 \\
\hline $\begin{array}{l}\text { Dactylorhiza incarnata (L.) Soó } \\
\text { Blume }\end{array}$ & Orchidoideae & Orchideae/Orchidinae & terrestrial & Kew S1319-91 \\
\hline Epipactis helleborine (L.) Crantz & Epidendroideae & Neottieae & terrestrial & Denmark \\
\hline $\begin{array}{l}\text { Bletilla foliosa (King \& Pantl.) } \\
\text { Tang \& F.T.Wang }\end{array}$ & Epidendroideae & Arethuseae/Coelogyninae & terrestrial & 0105 \\
\hline Pholidota imbricata Hook. & Epidendroideae & Arethuseae/Coelogyninae & epiphyte & P1993.7876 \\
\hline Coelogyne lawrenceana Rolfe & Epidendroideae & Arethuseae/Coelogyninae & epiphyte & P1993-7210 \\
\hline Dendrochilum glumaceum Lindl. & Epidendroideae & Arethuseae/Coelogyninae & epiphyte & 0131 \\
\hline $\begin{array}{l}\text { Bulbophyllum fletcherianum } \\
\text { J.G. Fowler }\end{array}$ & Epidendroideae & $\begin{array}{l}\text { Malaxideae/ } \\
\text { Dendrobiinae }\end{array}$ & epiphyte & P2001.5015 \\
\hline $\begin{array}{l}\text { Dendrobium friedericksianum } \\
\text { Rchb.f. }\end{array}$ & Epidendroideae & Malaxideae/Dendrobiinae & epiphyte & 0109 \\
\hline $\begin{array}{l}\text { Grammatophyllum speciosum } \\
\text { Blume }\end{array}$ & Epidendroideae & Cymbidieae/Cymbidiinae & epiphyte & 0106 \\
\hline Phaius tankervilleae (Banks) Blume & Epidendroideae & Collabieae & terrestrial & $\begin{array}{l}\text { P2000.5207 } \\
0112 \\
\end{array}$ \\
\hline $\begin{array}{l}\text { Phalaenopsis aphrodite Rchb.f. ssp. } \\
\text { formosana Christenson }\end{array}$ & Epidendroideae & Vandeae/Aeridinae & epiphyte & $\begin{array}{l}\text { Taichung, } \\
\text { Taiwan }\end{array}$ \\
\hline $\begin{array}{l}\text { Trichoglottis triflora (Guillaumin) } \\
\text { Garay \& Seidenf. }\end{array}$ & Epidendroideae & Vandeae & epiphyte & 0134 \\
\hline
\end{tabular}

in orchid seed packets (Rasmussen \& Whigham, 1993), which were bundled and soaked in the stain overnight at room temperature. The packets were rinsed three times in Milli-Q water and subsequently air dried. From the packets the dry seeds were poured/brushed onto slides and observed in immersion oil under the cover slip. Staining was evaluated at 400× magnification on a Axioskop microscope with Axiocam 305 color camera (Zeiss, Jena, Germany). The length of seeds (including testa) was measured with the image analysis software Zen 2 Blue (Zeiss, Jena, Germany). Seed lengths of terrestrial and epiphytic species were compared by Mann-Whitney U-test. 
c. Uptake of water: To pursue previous results that seeds of epiphytic species take up water more rapidly, we used microscope cavity slides, and floated seeds direct from dry storage on a drop of water. Each slide being confined within a Petri dish, the water dried out in c. $24 \mathrm{~h}$, but some seeds took up water fast enough to get wetted by this procedure. After the addition of more water, a cover slip was mounted and the seeds observed unstained on a Laborlux microscope (Leitz, Wetzlar, Germany), equipped with a MC170 HD camera (Leica, Wetzlar, Germany) and Leica Application Suite version 4 with $z$-stacking. This software is able to combine numerous exposures with gradually changing focus to obtain images with enhanced depth of field.

d. Attachment of dry seeds on glass: Seeds direct from dry storage were placed on dry glass cavity slides, and adherence was tested 1) with the glass plate in vertical position, 2) after tapping the glass in vertical position onto the stage of an SZ60 stereo microscope (Olympus, Shinjuku, Japan). The number of seeds remaining was counted at each step, with one assessment for each species. An antistatic gun, "Static-off Am", UK was used to test if attachment could be attributed to static electricity. Performance of seeds from epiphytes and terrestrials, respectively, were ranked and compared by non-parametric analysis.

e. Attachment of previously wetted seeds on glass: Coverslips were removed from seeds wetted according to $\mathbf{c}$, and adherence to the glass tested as under $\mathrm{d}$.

\section{Results and discussion}

Since orchid seeds can rarely be handled individually it is technically challenging to weigh them, as outlined above. Hence, there are not many original sources to seed weights in orchids. Here we provide some data, together with seed length measurements. Weights of individual seeds ranged from $0.3 \mu \mathrm{g}$ (in Phalaenopsis) to nearly $5 \mu \mathrm{g}$, the maximum surprisingly obtained from an epiphytic species, Dendrochilum glomaceum (Fig. 1). This is within the range given in a survey by Arditti and Ghani (2000). Terrestrial species appeared to generally have heavier seeds but the difference was not statistically significant $(P>0.05)$. A test on seed length showed significantly longer seeds in the terrestrial group of species than in the epiphytes $(P<0.05$, Fig. 1). Seeds of Odontochilum and Neuwiedia were extraordinarily long compared to their weight, indicating very long extensions of the testa both at chalazal and micropylar ends. Both species are terrestrial.

Mucilage in seeds is either produced within testa cells (Van Caeseele et al., 1981) or deposited in cell walls and released by dissolution of the wall. Adaptations similar to those described by Barthlott and Ziegler (1980) for Chiloschista lunifera, with testa cell walls that dissolve and release spiral thickenings and mucilage, is known from other plant families as well (e.g. Gutterman et al., 1973). Ruthenium Red is a stain for pectinaceous substances and typically will react mostly with materials originating in the middle lamella. However, our species reacted quite variably to the stain. We could distinguish four reaction groups among the genera represented:

1. Very faint reaction: Cypripedium, Phalaenopsis, Trichoglottis, Dendrochilum.

2. Staining mainly of the embryo: Epipactis, Bletilla.

3. Distinct staining of anticlinal walls of the testa (then often also of embryo): Neuwiedia, Dactylorhiza, Odontochilum, Grammatophyllum, Phaius, Dendrobium, Coelogyne, Bulbophyllum.

4. Staining of both anticlinal and periclinal testa walls: Pholidota.

Thus, the most common reaction was staining of anticlinal testa walls without any of the periclinal ones. The staining reactions did not segregate different lifeforms or suggest any phylogenetic patterns, since representatives of various subfamilies were scattered among staining reactions.

There was no significant staining outside of the seeds that might indicate any Ruthenium-positive 


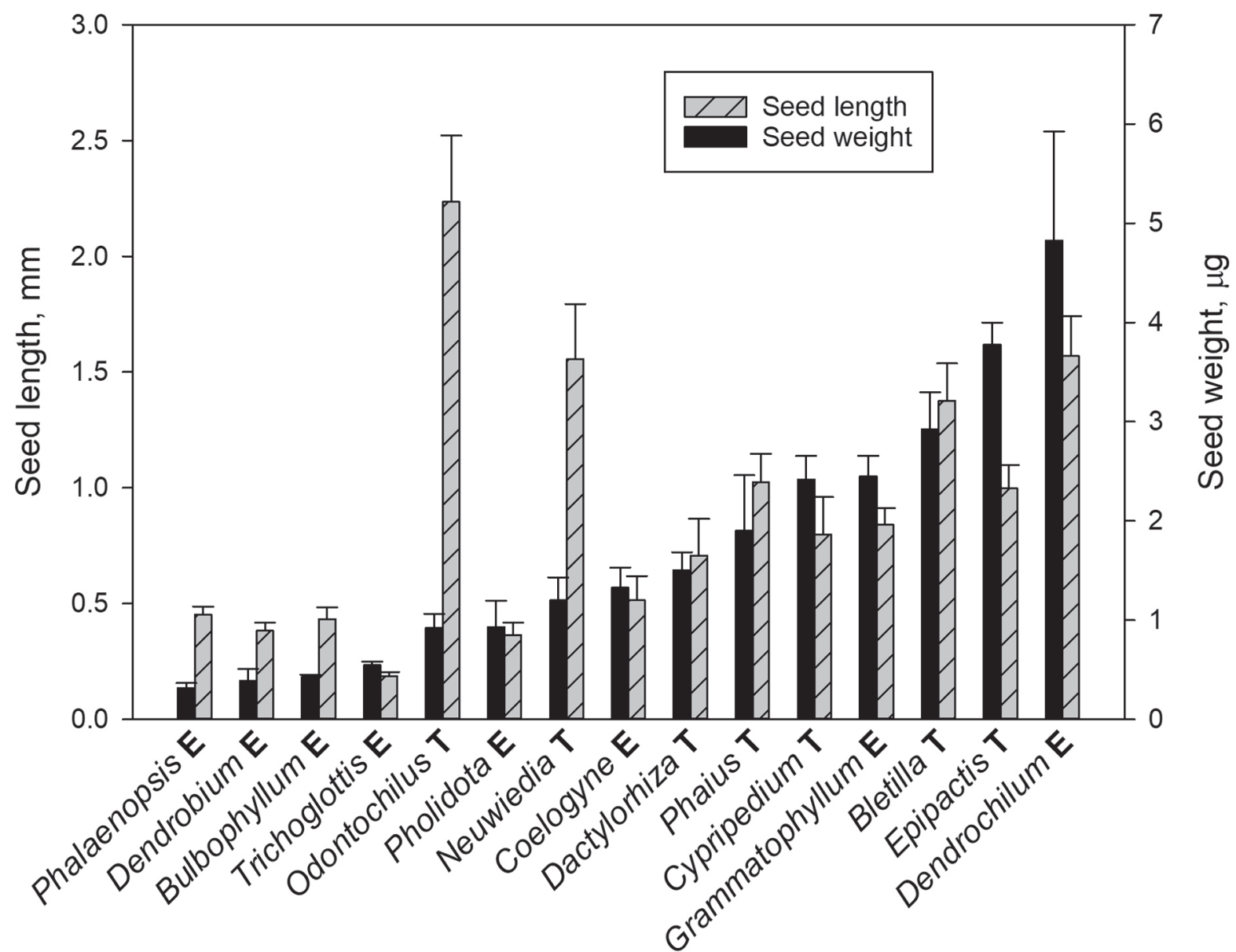

Fig. 1. Bar chart of seed weights and lengths in 15 orchid species. Arranged according to increasing weight. Means and standard deviation (error bars; $N=3$ for weight assessments, $N$ for length generally $\geq 10$, but Dactylorhiza only 2, Neuwiedia 3, Trichoglottis 4, Odontochilus 7 and Phaius 8). T and E refer to lifeform, terrestrial and epiphytic, respectively. All species referred to by generic name only, see Table 1 for species names.

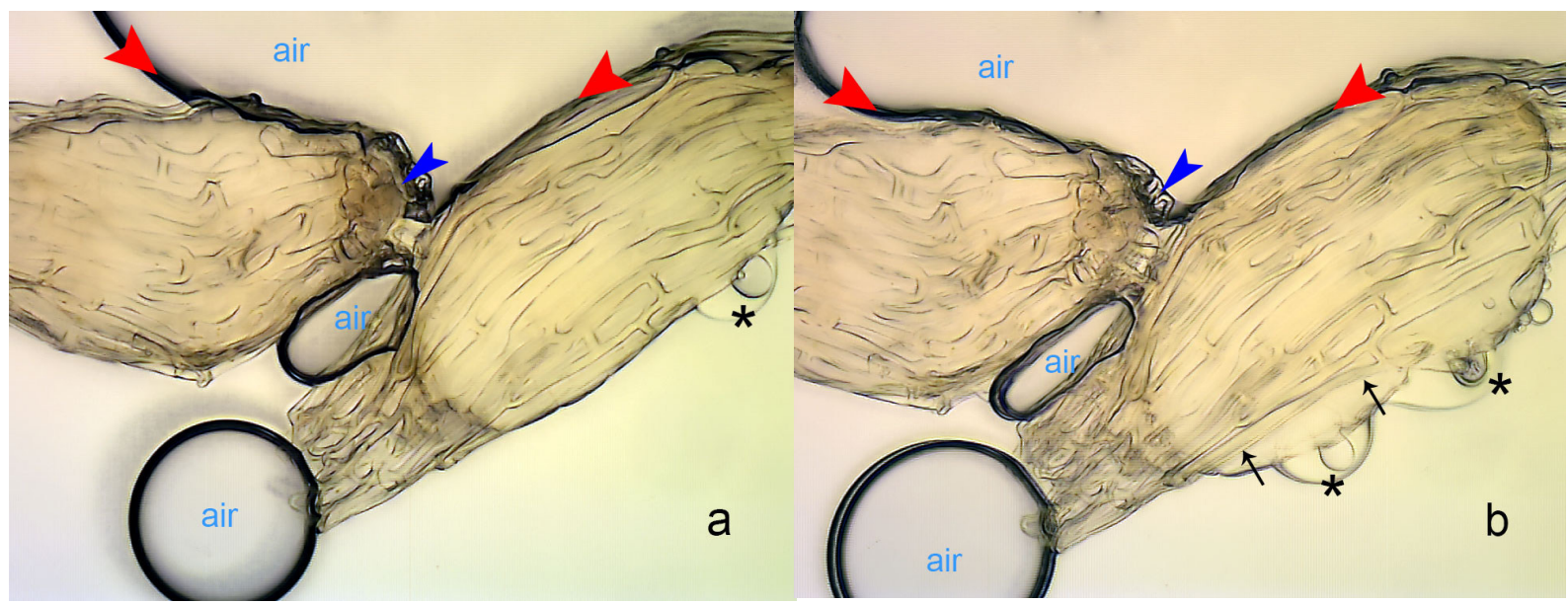

Fig. 2. Germinating seeds of Pholidota imbricata Hook.. Untreated seeds exposed to Milli-Q water for 21 hours (a) and 20 minutes later (b). Two seeds are assembled at the air-water interface (red arrowheads), with micropyle of the left seed projecting into the air (blue arrow). One small air bubble is trapped between the seeds, and a larger one is leaving the micropyle of the seed on the right. From $\mathbf{a}$ to $\mathbf{b}$ the embryo has swelled, the testa is ruptured (arrows in b) and rhizoids are developing (asterisks). Photographed under cover slip in Leitz Laborlux microscope with focus enhancing software at $400 \mathrm{x}$ magnification. The seeds are c. $0.5 \mathrm{~mm}$ long. 


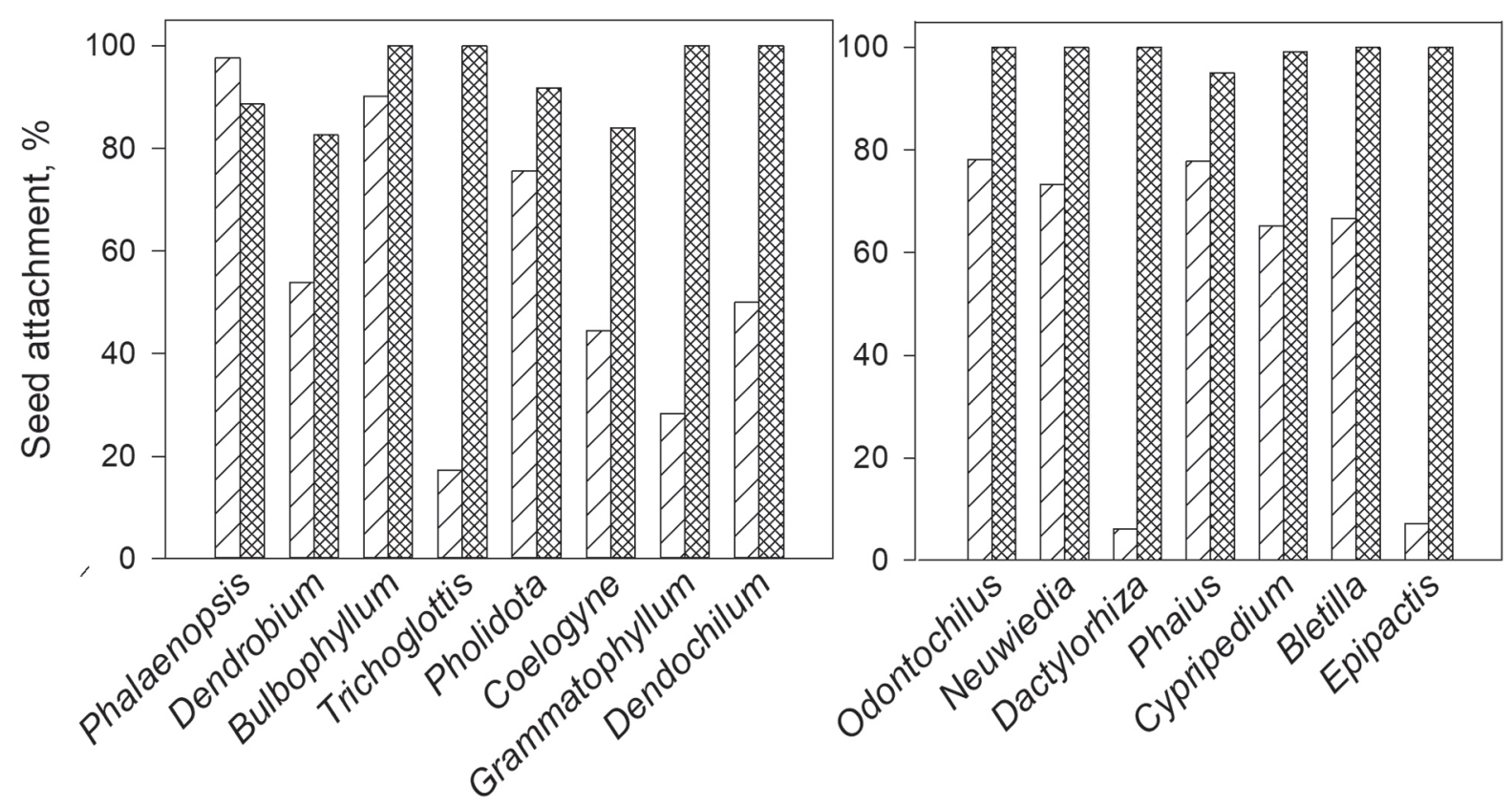

Fig. 3. Bar charts of retention of seeds on glass surfaces. Species divided by lifeform: epiphytic (left) and terrestrial (right), and arranged by increasing seed weight from left to right in each graph. Hatched bars: attachment of dry seeds, checkered bars: attachment of previously soaked seeds. All species referred to by generic name only, see Table 1 for species names.

secretion from them. However, we did observe some testa cell dissolution in the imbibed (but otherwise untreated) seeds of Trichoglottis and Phaius, an epiphytic and a terrestrial representative.

Untreated seeds, with surface chemistry intact, immediately floated when in touch with a water film. None of them sank during the observation period (24 h) or were able to sink when exposure to water was repeated after drying. A changeable humidity would seem to be the best imitation of natural conditions. Air bubbles were trapped on rims and in cavities of the testa surface, and within the lumen around the embryo, from which the air was gradually released through the micropyle (Fig. 2a). The micropyle appeared to be very wide in most species, and often fringed. In spite that hydration was not complete, sufficient water uptake was possible to initiate germination in at least three species: Dendrobium, Dendrochilum, and Pholidota (Fig. 2b), all epiphytes. Complete hydration appeared not to be essential for germination. The most rapid germination was seen within 10-15 h. Rapid germination could be a strategy for epiphytic species to stay attached, because bursting of the testa will release the seedling from its floating apparatus, and allow the entry of mycorrhizal hyphae through rhizoids, which may help to anchor the seedling to its substrate.

We tested the attachment of the seeds to a glass slide to simulate a very smooth bark surface. Turning the glass to vertical had negligible effect on the dry seeds of all species; they stayed in place (data not shown). When we applied an anti-static gun we saw no loosening of the seeds, indicating that the attachment was not due to static electricity. However, if the edge of the glass was tapped once onto a hard surface, some seeds dropped off, retention varying from $4-100 \%$ (Fig. 3, hatched bars). No significant difference was found between the behaviour of the terrestrial and the epiphytic group of seeds. In seeds that had previously been soaked and subsequently air dried, the attachment typically improved (Fig. 3, checkered bars), but again with no significant difference between terrestrial and epiphytic seeds. The improved attachment seems an indirect evidence that addition of water made the seeds stickier by some chemical changes in the testa surface, irrespective of the habitat of the seeds. 


\section{Conclusions}

This extent to which a selection of 15 species can represent a family of more than 20.000 species is clearly limited. We also cannot control how well the selected species represent the genera and tribes they belong to. Seed attachment was only assessed once for each species, and hopefully such tests can be carried out with freshly collected seeds and more species in future studies.

With these caveats, our data support that seeds in epiphytic orchid species tend to be shorter than in terrestrial species.

We observed fast germination in some epiphytic species (15-20 h) after exposure of the untreated seeds to water. This is consistent with previous reports of rapid water uptake in epiphytes.

We could not trace original sources to the information that orchid seeds produce mucilage. We found differential reaction to Ruthenium Red, but no consistency with respect to life form, and no clear evidence that staining was due to mucilage production.

In most species, previous wetting improved attachment. When the species groups were compared we found no difference in the behaviour of epiphytic seeds versus those of terrestrials.

\section{Acknowledgements}

Henrik Ærenlund Pedersen (Denmark), Yung-I Lee (Taiwan), and Royal Botanic Gardens, Kew kindly donated seeds for this study.

\section{Literature Cited}

ARDITTI J. \& A.K.A. GHANI 2000. Numerical and physical properties of orchid seeds and their biological implications. New Phytologist 145: 367-421. https:// doi.org/10.1046/j.1469-8137.2000.00587.x.

BARSBERG S., LEE Y.I. \& H.N. RASMUSSEN 2018. Development of C-lignin with G/S-lignin and lipids in orchid seed coats - an unexpected diversity exposed by ATR-FTIR spectroscopy. Seed Science Research 28: 4151. https://doi.org/10.1017/S0960258517000344

BARTHLOTT W. \& B. ZIEGLER 1980. Über ausziehbare helicale Zellwandverdickungen als Haftapparat der
Samenschalen von Chiloschista lunifera (Orchidaceae). Berichte der Deutschen Botanischen Gesellschaft 93: 391403.

BARTHLOTT W., GROBE-VELDMANN B. \& N. KOROTKOVA 2014. Orchid seed diversity: a scanning electron microscopy survey. Englera 32: 1-245.

BEER J.G. 1863. Beiträge zur Morphologie und Biologie der Familie der Orchideen. Druck und Verlag von Carl Gerold's Sohn, Wien.

CHASE M.W., CAMERON K.M., FREUDENSTEIN J.V., PRIDGEON A.M., SALAZAR G., VAN DEN BERG C. \& A. SCHUITEMAN 2015. An updated classification of the Orchidaceae. Botanical Journal of the Linnean Society 177: 151-174. https://doi.org/10.1111/ boj.12234

GRUBERT M. 1974. Studies on the distribution of myxospermy among seeds and fruits of Angiospermae and its ecological importance. Acta Biologica Venezuelica 8: 315-551.

GRUBERT M. 1981. Mucilage or gum in seeds and fruits of angiospermae. A review. Minerva-Publikation, München.

GUTTERMAN Y., WITZTUM A. \& W. HEYDECKER 1973. Studies of the surfaces of desert plant seeds: II. Ecological adaptations of the seeds of Blepharis persica. Annals of Botany 37: 1051-1055. https://doi.org/10.1093/ oxfordjournals.aob.a084770

NETOLITZSKY F. 1926. Anatomie der AngiospermenSamen. In: LINSBAUER K. (ed.), Handbuch der Pflanzenanatomie X. pp. 1-364. Gebrüder Bornträger, Berlin.

PAMMEL L.H. 1892. On the seed-coats of the genus Euphorbia. Transactions of the Academy of Sciences, St Louis 5: 543-568.

PEDERSEN H.Æ., RASMUSSEN H.N., KAHANDAWALA I.M. \& M.F. FAY 2012. Genetic diversity, compatibility patterns, and seed quality in isolated populations of Cypripedium calceolus (Orchidaceae). Conservation Genetics 13: 89-98. https:// doi.org/10.1007/s10592-011-0267-0

RASMUSSEN H.N. \& D.F. WHIGHAM 1993. Seed ecology of dust seeds in situ: a new study technique and its application in terrestrial orchids. American Journal of Botany 80: 1374-1378. https://doi.org/10.1002/J.15372197.1993.TB15381.X

TSUTSUMI C., MIYOSHI K., YUKAWA T. \& M. KATO 2011. Responses of seed germination and protocorm formation to light intensity and temperature in epiphytic and terrestrial Liparis (Orchidaceae). Botany 89: 841848. https://doi.org/10.1139/b11-066

VAN CAESEELE L., MILLS J.T.M., SUMNER M. \& R. GILLESPIE 1981. Cytology of mucilage production in 
the seed coat of candle canola (Brassica campestris). Canadian Journal of Botany 59: 292-300. https://doi.org/ 10.1139/b81-042

WCSP 2020. World Checklist of Selected Plant Families. Facilitated by the Royal Botanic Gardens, Kew. Available at: http://wcsp.science.kew.org/ (Accessed on 9.01.2020).

YODER J.A., ZETTLER L.W. \& S.L. STEWART 2000. Water requirements of terrestrial and epiphytic orchid seeds and seedlings, and evidence for water uptake by means of mycotrophy. Plant Science 156: 145-150. https:// doi.org/10.1016/s0168-9452(00)00246-6

YODER J.A., IMFELD S.M., HEYDECKER D.J., HART C.E., COLliER M.H., GRIBBINS K.M. \& L.W. ZETTLER 2010. Comparative water balance profiles of Orchidaceae seeds for epiphytic and terrestrial taxa endemic to North America. Plant Ecology 211: 7-17. https://doi.org/10.1007/s11258-010-9765-2 